\title{
A coopetição e os APL como indutores do desenvolvimento local: um panorama no Estado do Paraná
}

\author{
The coopetition and clusters as inducers of local development: an overview of the \\ State of Paraná
}

\author{
Tiago Hideki Niwa \\ Universidade Tecnológica Federal do Paraná
}

Isaura Alberton de Lima

Universidade Tecnológica Federal do Paraná

\author{
Christian Luiz da Silva \\ Universidade Tecnológica Federal do Paraná
}

\begin{abstract}
Resumo: A partir da consolidação de uma aglomeração produtiva, os Arranjos Produtivos Locais em consonância aos princípios e teorias desenvolvimentistas são indutores do desenvolvimento local. Por meio de uma metodologia de pesquisa exploratória, o estudo tem como objetivo, especialmente, demonstrar referências bibliográficas e dados oficiais de governo acerca dos arranjos produtivos locais, desenvolvimento local e regional, coopetição, inovação e empreendedorismo. Como principais resultados, destaca-se o protagonismo do governo e seus órgãos, bem como de instituições de ensino e pesquisa para mediar ações de desenvolvimento local, enquanto agentes indutores para identificação e fortalecimento das vocações produtivas territoriais. Por isso, embora haja a identificação das aglomerações produtivas, inclusive por meio de órgãos oficiais de governo, faz-se importante a discussão entre os agentes promotores dos APL para averiguar interesses econômicos, sociais e ambientais, assim como as potencialidades e vantajosidades para o desenvolvimento sistemático de determinados produtos ou serviços.
\end{abstract}

Palavras-chave: Arranjos produtivos locais; Coopetição; Desenvolvimento regional; Empreendedorismo; Inovação.

\begin{abstract}
From the consolidation of productive concentration, the clusters in line with the principles and developmental theories are inducers of local development. Through an exploratory research methodology, the study aims, in particular, demonstrate references and official government data about the local productive arrangements, local and regional development, coopetition, innovation and entrepreneurship. The main results highlight the role of the government and its agencies as well as educational and research institutions to mediate actions of local development, while inducing agents for identifying and strengthening the territorial productive vocations. Therefore, although there is the identification of productive clusters, including through official government agencies, it is important to discuss among promoters of clusters to investigate economic, social and environmental concerns, and the potential and benefits for a systematic development for certain products or services.
\end{abstract}

Keywords: Local clusters; Coopetition; Regional development; entrepreneurship; Innovation.

JEL: O32; R11

\section{Introdução}

A aglomeração de instituições, indivíduos e interesses de forma organizada é indutora do desenvolvimento tendo em vista a sinergia em torno de uma especificidade produtiva. Em razão disso, tais aglomerações produtivas em determinado território podem ocasionar uma organização formal, estabelecendo-se governança e indicadores, atribuindo-lhes diversas denominações: clusters, arranjos produtivos locais, sistemas produtivos locais, entre outros. Por isso, o cerne do desenvolvimento, de acordo com alguns estudiosos, tem fundamento nas formas de 
relações e investimentos empresariais e institucionais para a produção, inovação e, consequentemente, o desenvolvimento econômico e social (PLONSKI, 2005).

Dessa forma, ainda que existam diversos estudos acerca dos Arranjos Produtivos Locais (APL), faz-se importante a discussão haja vista que se trata de um tema recorrente nas mesas de discussões de desenvolvimento, bem como pela possibilidade de fortalecimento das estruturas e sistemas existentes. Ante os conceitos já delineados pela doutrina especializada, é mister refletir sobre possíveis caminhos que induzem o desenvolvimento local a partir da sinergia de empresas, governo, instituições de ensino e pesquisa, entidades de fomento, entre outros, de forma a atingir o equilíbrio entre a competitividade e a cooperação entre esses agentes.

Por isso, o segundo momento de argumentação aborda o papel dos agentes promotores de APL, bem como a importância do prévio acordo à sistemática em que são inseridos. A finalidade é o desenvolvimento e o crescimento econômico e social, muitas vezes relegados ao individualismo e a falta de organização. Nesse sentido, o governo e seus órgãos, bem como as instituições de ensino e pesquisa possuem importante atribuição de comandar, mediar e induzir a formação e organização de APL e demais questões para o desenvolvimento local.

Dada à ampla discussão que existe sobre o tema, não é possível abranger todos os estudos realizados, mas se pretende demonstrar pontos relevantes para a subsunção à realidade brasileira. Os pontos destacados visam, em um terceiro e derradeiro momento, demonstrar ilustrativamente o caso do Estado do Paraná, como forma de relacionar algumas formações de APL.

Destaca-se, ainda, que o desenvolvimento local é multifatorial, cuja complexidade repousa, especialmente, sobre diferentes variáveis econômicas, políticas, sociais, culturais, históricas e tecnológicas. No mesmo sentido, para um desenvolvimento sustentável as dimensões repousam, dentre outras, sobre questões sociais, econômicas, ambientais, espaciais e culturais (MARINI e SILVA, 2012). Ademais, as relações das empresas e instituições devem estabelecer os limites, seja da cooperação entre eles, seja da competição natural de um sistema capitalista. Esse fenômeno é conhecido como coopetição, cuja aplicação é realizada em planejamentos estratégicos de empresas e cujas medidas e valorações de cooperação e competição são voltadas para o desenvolvimento (BRANDENBURGER e NALEBUFF, 2011).

Portanto, os arranjos produtivos locais em consonância com teorias de desenvolvimento econômico, dentre elas, a coopetição de empresas, podem ser indutores do desenvolvimento local, sendo o que se propõe discorrer no presente artigo científico. Por isso, destaca-se a relevância do tema a partir da preocupação para com o desenvolvimento econômico e social de uma delimitação territorial por meio de ações conjuntas de entidades promotoras de arranjos produtivos locais.

\section{Metodologia}

A demonstração do estudo é realizada por meio de um método de pesquisa exploratório e descritivo, buscando-se, em especial, demonstrar as referências bibliográficas e dados oficiais de governo a respeito dos Arranjos Produtivos Locais, desenvolvimento local e regional, inovação e empreendedorismo, conjuntamente sob a égide da boa governança e de teorias de desenvolvimento econômico e social.

Apresentam-se dados oficiais a respeito dos APL no Estado do Paraná, bem como uma síntese de entrevista realizada com a Assessora Técnica de Planejamento,

Informe Gepec, Toledo, v. 18, n. 2, p. 66-85, jul./dez. 2014 
da Coordenação de Desenvolvimento Governamental, da Secretaria do Planejamento e Coordenação Geral do Estado do Paraná (SEPL).

\section{A formação e sistematização de Arranjos Produtivos Locais para o desenvolvimento local}

O desenvolvimento econômico de uma localidade possui diferentes e complexas características, haja vista a variedade de influências sobre os fatores produtivos. Contudo, acredita-se que determinadas especificidades podem contribuir para o desenvolvimento local a partir de políticas positivas que corroboram a uma natural regulação de mercado. Significa que políticas oriundas tanto de entidades públicas, quanto privadas, podem estabelecer novos horizontes para o desenvolvimento. Portanto, o enfoque na cadeia produtiva dos Arranjos Produtivos Locais (APL) é um aspecto de estudo para a indução do desenvolvimento.

Ademais, o desenvolvimento local pode se entender como uma série de aprimoramentos em determinada delimitação espacial, concebida esta como uma junção de características das proximidades (sejam de dimensões geográficas, organizacionais ou territoriais) (BENKO; PECQUEUR, 2009). Envolve, então, um entendimento territorial de desenvolvimento, por uma questão de interesse políticoinstitucional, mas cujas influências podem ter abrangência global. Quer dizer que a noção de um estudo de delimitações espaciais pode influir em questões territoriais e regionais, dependendo do objeto de pesquisa (THEIS; GALVÃO, 2012, p. 62).

Nesse prisma, os atores locais são responsáveis por determinar o desenvolvimento do território, haja vista que são conhecedores das redes existentes; das potencialidades e vocações da localidade; dos recursos naturais disponíveis; da cultura empreendedora e local; do capital humano e social; das vantagens competitivas do local; dentre outros fatores. Da mesma forma, vale destacar que cada APL tem uma identidade diferente e peculiar dada a heterogeneidade de sua composição e formação (SEBRAE, 2003).

Os Arranjos Produtivos Locais, enquanto uma concentração de atores locais em um determinado território, apresentando especialização produtiva e interações entre agentes, podem apresentar mecanismos de desenvolvimento local a partir de uma organização produtiva. Portanto, há uma cooperação e articulação entre as empresas e o governo, entre associações empresariais, instituições de ensino e de pesquisa, fontes de fomento, entre outros atores que corroboram para o fortalecimento do empreendedorismo e inovação de uma localidade (MDIC, 2013).

Nesse sentido, o desenvolvimento regionalizado tende a fortalecer as estruturas de produção e da indústria capitalista em um movimento de descentralização de capitais e ao mesmo tempo de centralização de comandos e controle dos mesmos. Entende-se, então, que a estratégia de descentralização de ações com a centralização e comando de capitais é importante para o desenvolvimento econômico, de acordo com as características do trabalho, das mercadorias, do capital e de poderes econômicos (GALVÃO, 2004).

Dentre os termos utilizados para Arranjos Produtivos Locais, citam-se diversos outros mencionados pela literatura nacional e estrangeira, tais como: sistemas produtivos locais, distritos industriais, clusters, tecnopólos, sistemas locais de produção, millieux innovateurs, entre outros (MARINI; SILVA, 2012, p. 118). Porter (1998), dentre tantas outras contribuições para a Economia, lançou o termo cluster para descrever a competitividade e estratégias entre aglomerações de empresas,

Informe Gepec, Toledo, v. 18, n. 2, p. 66-85, jul./dez. 2014 
legado este que perdura para os estudos relacionados aos Arranjos Produtivos Locais. Ademais, a sigla APL, no Brasil, bem como o termo "Arranjos Produtivos Locais", foram lançados no final da década de 1990 a partir de discussões no Ministério de Ciência e Tecnologia (MCT) (COSTA, 2010).

Para a Redesist (Rede de Pesquisa em Sistemas Produtivos e Inovativos Locais), formalizada desde 1997 e sediada no Instituto de Economia da Universidade Federal do Rio de Janeiro (UFRJ), os arranjos e sistemas produtivos locais podem ser entendidos como (MDIC, 2013): vínculos entre agentes econômicos, políticos e sociais em determinada aglomeração territorial, bem como a participação e interação de empresas e de variadas organizações públicas e privadas (formação e capacitação de recursos humanos; instituições de ensino e pesquisa; e política, promoção e financiamento) (CASSIOLATO; LASTRES, 2003, p. 5).

A importância dos APL para o desenvolvimento local relaciona-se, especialmente, ao crescimento e sobrevivência de empresas (em especial as de pequeno e médio porte) no mercado, a partir da sinergia entre os atores locais, trazendo-lhes benefícios duradouros (CASSIOLATO; LASTRES, 2003). Trata-se de uma miscelânea de serviços e produtos por meio da cooperação entre si para o crescimento de todos e, consequentemente, para o desenvolvimento local (com possíveis reflexos regionais e globais).

Portanto, o reconhecimento de um APL ocorre a partir da caracterização, em determinado território, de número significativo de empreendimentos e de indivíduos que atuem em uma atividade produtiva predominante, havendo alguma forma de governança e cooperação entre esses agentes. Ademais, tal detalhamento dessa caracterização de um APL pode ser encontrado no "Termo de Referência para Política de Apoio ao Desenvolvimento dos Arranjos Produtivos Locais”, elaborado pelo Grupo de Trabalho Permanente para APL (GTP-APL), coordenado pelo Ministério do Desenvolvimento, Indústria e Comércio Exterior do Governo Federal (MDIC, 2013).

Várias são as experiências internacionais para a promoção de vocações territoriais e produtivas em matéria de inovação e empreendedorismo, tais como as da União Europeia, Espanha, Finlândia, Itália, Reino Unido, Holanda, Coréia do Sul e França, cada qual com suas peculiaridades sociais, jurídicas e culturais, com políticas próprias e de acordo com a realidade local ou regional (LEMOS, 2001, p. 23). Ainda, Perroux (1950) lecionava a respeito dos espaços econômicos e polos de crescimento, cuja teoria demonstrava o espaço definido por um planejamento, enquanto um campo de forças e de agregação homogênea.

No Brasil, a atenção voltada aos APL se deu de forma acelerada a partir do final dos anos 1990, sendo incluídos nas agendas políticas para o desenvolvimento econômico. Por isso, a relevância que foi dada aos APL ocasionou à inclusão em planos plurianuais e planos nacionais de governo, bem como em políticas de desenvolvimento. A discussão deixou a esfera federal para alcançar os governos e entidades estaduais e municipais, bem como alcançar instituições públicas e privadas que são atores importantes para a consolidação do entrelaçamento dos APL (MDIC, 2013).

Tais proliferações fizeram surgir estudos diversificados acerca de sistemas de produção e inovação, eclodindo em modelos e estruturas de desenvolvimento, considerando, cada qual, questões de ordem regional, cultural, social, tecnológica ou organizacional (MDIC, 2013). A avaliação deste ou aquele estudo como mais apropriado para o desenvolvimento local é de difícil mensuração, haja vista a complexidade de fatores para o sucesso, bem como o papel do próprio mercado para regular o desempenho das atividades econômicas (CÂNDIDO, 2001). 
De qualquer sorte, o papel dos APL no desenvolvimento local, inclusive para contribuir para a inovação tecnológica, é relevante. A inovação tecnológica, enquanto caracterizada em promover mudanças em produtos ou processos que envolvem tecnologia, é fator essencial de desenvolvimento para o empreendedorismo nacional. Todavia, diversos equívocos devem ser desconstruídos no que concerne à inovação tecnológica no Brasil, sendo que a sua valorização pode ser embasada em políticas de inovação que, dentre elas, cita-se o reconhecimento de um caráter sistêmico e autocoordenado das inovações tecnológicas (PLONSKI, 2005, p. 30).

Assim, a inovação é um indicador importante para medir o desenvolvimento de uma nação, que é realizado por meio da assimilação da inovação pelas empresas e pelos fatores de produção. E essa cooperação mútua ocorre por meio de facilitadores, tais como do governo federal e estadual, institutos de ciência e tecnologia, bem como de entidades públicas e privadas (MOURO, 2013, p. 28). Trata-se de um conjunto de ações que corroboram para o desenvolvimento local.

Todavia, como identificar os arranjos produtivos locais? Para essa questão, faz-se relevante citar a pesquisa de Crocco et al. (2003) os quais estabeleceram critérios e indicadores para identificar as aglomerações produtivas locais: a) a especificidade de um setor em determinada região, utilizando-se do Quociente Locacional; b) o peso desse setor na indústria da região, com base no índice Hirschman-Herfindahl modificado $(\mathrm{HHm})$; c) a relevância do setor no âmbito nacional; d) a escala absoluta da estrutura da indústria local (CROCCO et al., 2003, p. 5). Tal estudo antecipa algumas etapas para a mensuração dos arranjos produtivos locais, mas, logicamente, não esgota a caracterização dos mesmos.

Por isso, o "Termo de Referência para a Atuação do Sistema SEBRAE em Arranjos Produtivos Locais" é uma ferramenta que permite esclarecer quanto à caracterização de um APL até a sua estruturação e avaliação, sendo uma referência importante para o Sistema SEBRAE. Esse material, então, descreve quatro componentes para o desenvolvimento de um APL, além de um componente preliminar, demonstrado no Quadro 01.

Quadro 01 - Componentes para o Desenvolvimento de um APL

\begin{tabular}{|l|l|}
\hline \multicolumn{1}{|c|}{ Componentes } & \multicolumn{1}{c|}{ Características } \\
\hline $\begin{array}{l}\text { Componente I: Fortalecimento da } \\
\text { dinâmica do APL (articulação, } \\
\text { sensibilização e mobilização dos } \\
\text { atores locais). }\end{array}$ & $\begin{array}{l}\text { As ações desse fortalecimento da dinâmica do APL se } \\
\text { dão por meio de três dimensões: a) governança; b) } \\
\text { identidade territorial; c) interação e cooperação. }\end{array}$ \\
\hline $\begin{array}{l}\text { Componente II: Conhecimento } \\
\text { do ambiente competitivo. }\end{array}$ & $\begin{array}{l}\text { Neste componente consideram-se três dimensões de } \\
\text { competitividade: a) empresa; b) estrutura; c) sistema. } \\
\text { Bem como também se consideram dois eixos pelas quais } \\
\text { as ações se desenvolverão: a) eixo do mercado; b) eixo } \\
\text { da produção. }\end{array}$ \\
\hline $\begin{array}{l}\text { Componente III: Elaboração dos } \\
\text { planos de desenvolvimento. }\end{array}$ & $\begin{array}{l}\text { A partir dos diagnósticos de competitividade, torna } \\
\text { possível a elaboração de um planejamento estratégico. É } \\
\text { importante que haja um plano de curto e outro de longo } \\
\text { prazo, com os detalhamentos que cada qual exige. }\end{array}$ \\
\hline $\begin{array}{l}\text { Componente IV: Gestão, } \\
\text { desenvolvimento e avaliação. }\end{array}$ & $\begin{array}{l}\text { Faz-se importante a elaboração de metas e indicadores } \\
\text { para o acompanhamento e avaliação das ações } \\
\text { desenvolvidas nos APL. Da mesma forma, que haja } \\
\text { mecanismos para mensurar os impactos e } \\
\text { sustentabilidade dessas ações. }\end{array}$ \\
\hline
\end{tabular}

Fonte: Quadro elaborado pelos autores a partir de dados do SEBRAE (2003).

Informe Gepec, Toledo, v. 18, n. 2, p. 66-85, jul./dez. 2014 
Nesse sentido, os componentes para o desenvolvimento de um APL enquanto referência para o SEBRAE podem ser ilustrados de acordo com a Figura o1.

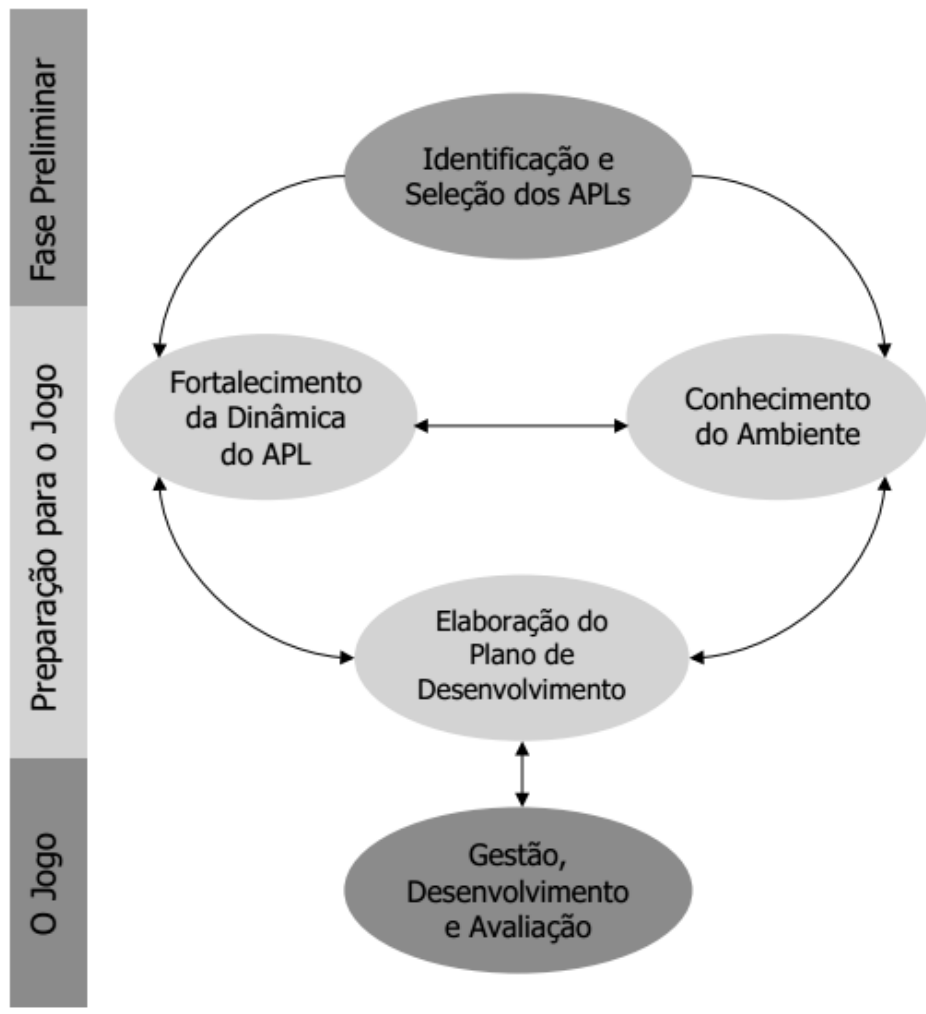

Figura 01 - SEBRAE

Fonte: SEBRAE (2003, p. 21)

O reconhecimento de um APL, de acordo com o Observatório Brasileiro de Arranjos Produtivos Locais (OBAPL), ocorre a partir do cumprimento de um conjunto de variáveis que caracteriza determinado aglomerado como APL, o que está prescrito no "Termo de Referência para Política de Apoio ao Desenvolvimento dos Arranjos Produtivos Locais" (elaborado pelo Grupo de Trabalho Permanente para Arranjos Produtivos Locais - GTP APL): a) possuir significativo número de empreendimentos e indivíduos em um território no qual há uma atividade produtiva predominante; b) existir formas de cooperação e mecanismos de governança, podendo incluir pequenas, médias e grandes empresas (OBAPL, 2014).

Para o Instituto Paranaense de Desenvolvimento Econômico e Social (IPARDES), a identificação de um APL no âmbito do Estado do Paraná baseia-se em três variáveis: a) quociente locacional das classes de atividades por microrregião; b) número de estabelecimentos da classe de atividade por microrregião; e c) número de empregos formais da classe de atividade por microrregião (IPARDES, 2009). Significa, então, que os critérios de identificação e caracterização de APL são variáveis, mas com características em comum, conforme demonstrado no Quadro 2. 


\begin{tabular}{|c|c|}
\hline \multicolumn{2}{|r|}{ Quadro 2 - Formas de identificação de APL } \\
\hline Entidade & Características \\
\hline $\begin{array}{l}\text { MDIC } \\
(2013)\end{array}$ & $\begin{array}{l}\text { O MDIC infere que a identificação de um APL ocorre a partir da caracterização, } \\
\text { em determinado território, de número significativo de empreendimentos e de } \\
\text { indivíduos que atuem em uma atividade produtiva predominante, assim como } \\
\text { haja alguma forma de governança e cooperação entre esses agentes, o que pode } \\
\text { ser encontrado no "Termo de Referência para Política de Apoio ao } \\
\text { Desenvolvimento dos Arranjos Produtivos Locais", elaborado pelo Grupo de } \\
\text { Trabalho Permanente para APL (GTP-APL). }\end{array}$ \\
\hline $\begin{array}{l}\text { Crocco et } \\
\text { al (2003) }\end{array}$ & $\begin{array}{l}\text { Crocco et al (2003) estabeleceram critérios e indicadores para identificar as } \\
\text { aglomerações produtivas locais: a) a especificidade de um setor em determinada } \\
\text { região, utilizando-se do Quociente Locacional; b) o peso desse setor na indústria } \\
\text { da região, com base no índice Hirschman-Herfindahl modificado (HHm); c) a } \\
\text { relevância do setor no âmbito nacional; e d) a escala absoluta da estrutura da } \\
\text { indústria local }\end{array}$ \\
\hline $\begin{array}{l}\text { OBAPL } \\
(2014)\end{array}$ & $\begin{array}{l}\text { O Observatório Brasileiro de Arranjos Produtivos Locais (OBAPL) considera um } \\
\text { APL a partir do cumprimento de um conjunto de variáveis que caracteriza } \\
\text { determinado aglomerado produtivo, o que está prescrito no "Termo de } \\
\text { Referência para Política de Apoio ao Desenvolvimento dos Arranjos Produtivos } \\
\text { Locais" (elaborado pelo Grupo de Trabalho Permanente para Arranjos } \\
\text { Produtivos Locais - GTP APL): a) possuir significativo número de } \\
\text { empreendimentos e indivíduos em um território no qual há uma atividade } \\
\text { produtiva predominante; b) existir formas de cooperação e mecanismos de } \\
\text { governança, podendo incluir pequenas, médias e grandes empresas (OBAPL, } \\
\text { 2014). }\end{array}$ \\
\hline $\begin{array}{l}\text { IPARDES } \\
(2009)\end{array}$ & $\begin{array}{l}\text { Para o Instituto Paranaense de Desenvolvimento Econômico e Social (IPARDES) } \\
\text { a identificação de um APL no âmbito do Estado do Paraná baseia-se em três } \\
\text { variáveis: a) quociente locacional das classes de atividades por microrregião; b) } \\
\text { número de estabelecimentos da classe de atividade por microrregião; e c) } \\
\text { número de empregos formais da classe de atividade por microrregião (IPARDES, } \\
\text { 2009). }\end{array}$ \\
\hline $\begin{array}{l}\text { Síntese } \\
\text { dos } \\
\text { autores }\end{array}$ & $\begin{array}{l}\text { Em que pese à possibilidade de diferentes critérios teórico-empíricos de } \\
\text { identificação de APL, averiguam-se elementos em comum na composição das } \\
\text { dimensões estudadas. O "Termo de Referência para Política de Apoio ao } \\
\text { Desenvolvimento dos Arranjos Produtivos Locais" apresenta-se como um } \\
\text { documento nacional para caracterização de APL, embora seja possível a } \\
\text { inferência de diversos indicadores para a dimensão de um APL, dada a } \\
\text { complexidade das relações entre os agentes de desenvolvimento. }\end{array}$ \\
\hline
\end{tabular}

Fonte: Quadro sinótico elaborado pelos autores a partir de dados do MDIC (2013); Crocco et al. (2003); OBAPL (2014); e IPARDES (2009).

Nessa esteira, sabe-se da importância da parceria e cooperação entre empresas e atores locais para o desenvolvimento, devendo-se contrabalancear com a natural concorrência que existe entre os mesmos. Portanto, Brandenburger e Nalebuff (2011) lançaram o termo "coopetição" para descrever as situações e os limites da cooperação e competição entre os agentes locais, a partir de casos reais de personagens e organizações. Descrevem, ainda, que o negócio é um jogo, cuja trilha a ser perseguida pode acarretar em sucessos ou insucessos, dependendo das regras a serem seguidas.

A coopetição enquanto um processo natural de mercado pode ser exemplificado com a indústria automobilística (Ford e General Motors nos Estados Unidos), cujos processos produtivos induzem outros negócios (complementos) a partir desse fato gerador (fornecimento de crédito bancário, seguro automobilístico, manutenção de veículos, entre outros) (BRANDENBURGER; NALEBUFF, 2011).

Informe Gepec, Toledo, v. 18, n. 2, p. 66-85, jul./dez. 2014 
Bengtsson e Kock (2000, p. 411) aduzem da complexidade, porém possibilidade, da simultaneidade da competição e cooperação entre empresas. Os autores apresentam que é possível haver a coopetição quando se compreendem e selecionam os graus de proximidade das empresas para com os consumidores, bem como o nível de acesso dos competidores em recursos específicos. Demonstram que há necessidade de entendimento e organização dentro das empresas de como separar o que é possível cooperar e o que é naturalmente da concorrência de mercado; ou mesmo apresentar a figura moderadora para regular ou controlar as ações de coopetição.

Trata-se de refletir a própria estrutura das organizações para saberem lidar com o conhecimento, a cooperação e a competitividade. Por isso, Tsai (2002, p. 180) assevera que a estrutura hierárquica formal, na forma centralizadora, pode ocasionar efeitos negativos no compartilhamento de conhecimentos. Já as relações laterais informais, na forma de interação social, apresentam resultados positivos para a partilha de conhecimentos entre organizações que competem entre si para uma divisão de mercado, mas não para o compartilhamento de recursos internos (Tsai, 2002, p. 180).

A pesquisa de Bengtsson e Kock (2000, p. 424) revelou que dentro da complexidade das relações competitivas e cooperativas entre agentes de desenvolvimento, verificou-se maior cooperação ou colaboração quando há maior distanciamento dos clientes (buyers), e maior competição quando há maior proximidade desses clientes. Significa que a cooperação pode estar presente em atividades como: a) a divisão de custos de produção para determinado produto; b) o encurtamento de prazos de entrega; e c) a contribuição de cada empresa com o conhecimento (know-how) (BENGTSSON; KOCK, 2000, p. 424).

A lógica de um negócio é realizada por fatores e pessoas que, invariavelmente, influenciam em seu sucesso. Há uma dependência entre determinados fatores que deve ser explorado para se formar uma rede e fazer o negócio alavancar. Brandenburger e Nalebuff (2011) citam os exemplos de casas noturnas, que oferecem algumas entradas e bebidas gratuitas a clientes para atrair outros consumidores que sustentam o negócio, bem como de empresas de jornais e revistas que possuem dois públicos diferentes e necessários: os leitores e os anunciantes. Contudo, vários são os fatores e valorações que se devem analisar para que se explore o negócio da melhor maneira, dentro de uma circunstância competitiva (limites da cooperação e competição; preservação de informações estratégicas; celebração de contratos com parceiros; entendimento das "regras do jogo") (BRANDENBURGER; NALEBUFF, 2011).

Destaca-se a complexidade dessas valorações entre cooperação e competição entre atores do desenvolvimento, haja vista que estudos mais aprofundados podem falhar ao quererem estabelecer um modelo de relação entre tais agentes. Por isso, a formação de estratégias de competição consistentes é relevante para se definir os interesses econômicos no âmbito privado, de forma a estabelecer e analisar as forças que exercem sobre a competitividade entre empresas (PORTER, 2004).

Portanto, a sinergia dos atores de produção é importante ao relacioná-los com os espaços e territórios nos quais eles exercem influências. Tal observação é relevante a partir das aglomerações de organizações em determinadas localidades, onde há competição e desenvolvimento econômico. Por isso, já foram amplamente discutidos acerca dos territórios da Terceira Itália e do Vale do Silício nos Estados Unidos, cujas aglomerações e sinergias produtivas acarretaram na formação de consistentes arranjos. Vale dizer, ainda, que as influências dos arranjos são complexas, tendo em vista a globalização, a profundidade do conhecimento técnico e tecnológico, bem

Informe Gepec, Toledo, v. 18, n. 2, p. 66-85, jul./dez. 2014 
como os níveis de influência que um negócio pode gerar (CASSIOLATO; LASTRES, 2003, p. 4).

Assim, não é possível dissociar o desenvolvimento econômico e a inovação das responsabilidades das instituições de ensino e pesquisa para o aprimoramento do conhecimento. O conhecimento acadêmico, técnico e tecnológico para a produção é essencial para a sobrevivência de um negócio a partir de parcerias estratégicas (ETZKOWITZ, 2013). Por isso, as universidades têm forte apelo para o desenvolvimento, servindo a indústria para a inovação de seus produtos ou processos. Trata-se, então, da necessidade de aliar a produção acadêmica de instituições de ensino e pesquisa para com o desenvolvimento econômico (ETZKOWITZ; LEYDESDORFF, 2000).

Tal rede de conhecimento e produção foi batizada por Etzkowitz e Leydesdorff (1995) de modelo da Hélice Tríplice, cujos alicerces são as universidades, o governo e a indústria, formando uma relação trilateral e não-linear. Significa que há uma dinâmica complexa entre esses três elementos a partir da composição de novas dinâmicas, como as forças do mercado, as forças políticas, os controles institucionais, os movimentos sociais, o desenvolvimento tecnológico, entre outros (ETZKOWITZ; LEYDESDORFF, 2000, p. 113). São variáveis e agentes que tornam a relação do conhecimento e da produção como algo criterioso e complexo.

Atualmente, a força da ciência para o desenvolvimento econômico se tornou fundamental para a competição regional e internacional. Vale dizer que o crescimento econômico é dependente do crescimento intelectual e tecnológico no que tange à sobrevivência do negócio. Por isso, as universidades são importantes laboratórios para a indústria, visando o desenvolvimento econômico e social (ETZKOWITZ; LEYDESDORFF, 2000, p. 117).

A formação de agentes empreendedores, especialmente em universidades, pode acarretar em economias baseadas no conhecimento e na ciência, gerando complexas relações entre o conhecimento e a produção, dentro de um entendimento regional ou internacional. Forma-se, então, um sistema de desenvolvimento que passa, inclusive, a gerar conhecimento e inovação dentro da própria rede cooperativa ou arranjo (endogenia). Ademais, é importante destacar a importância da localização geográfica dos geradores de conhecimento (tais como as universidades), bem como dos efeitos da globalização, a fim de se entender os movimentos de industrialização e desindustrialização; instalações de organizações multinacionais; e a versatilidade do uso, aprimoramento e transferência do conhecimento (regional, nacional ou internacionalmente) (LAWTON; LEYDESDORFF, 2012, p. 8). A Figura 02 representa as relações em uma economia baseada no conhecimento. 


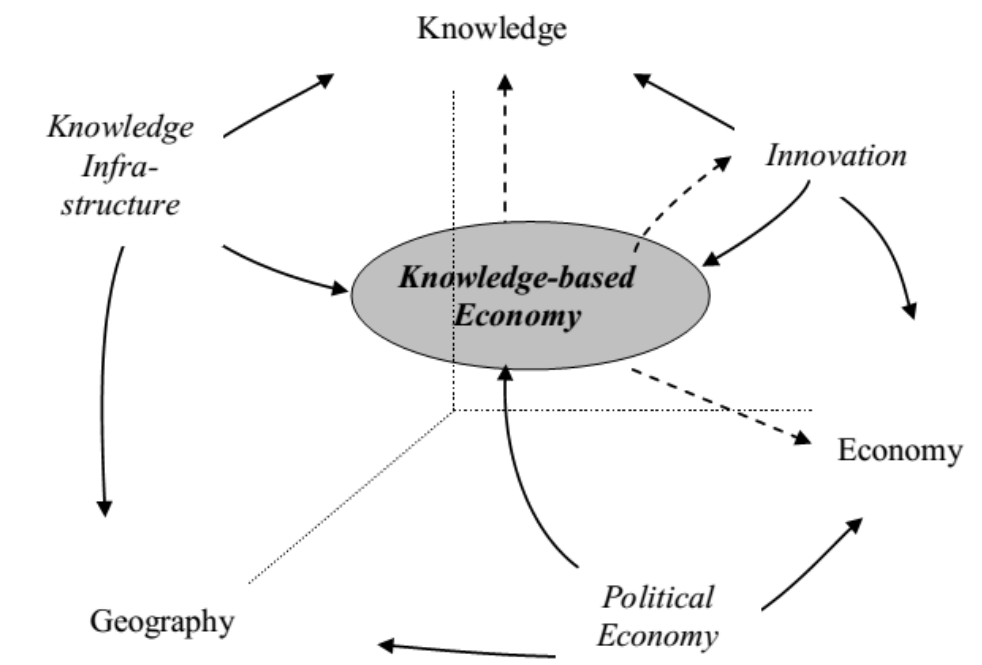

Figura 02 - Economia baseada no conhecimento

Fonte: Lawton e Leydesdorff (2012).

A partir dos entendimentos da formação e da importância de arranjos e de sistemas produtivos locais, bem como das diversas variáveis que compõem e instigam o desenvolvimento local, vale pontuar os agentes e órgãos promotores do desenvolvimento produtivo e inovativo. Logo após, e como forma de ilustrar o apanhado teórico até então desenvolvido, será possível reconhecer e refletir acerca dos APL no Estado do Paraná, como forma de aplicação prática do referencial teórico.

\section{Ações de agentes e órgãos promotores do desenvolvimento produtivo e inovativo}

Quando se discute sobre empreendedorismo, inovação e desenvolvimento econômico, vários são os temas que se interligam transversalmente, visto que as variáveis são ilimitadas e incondicionadas. Desta feita, diversos são os atores e agentes para o desenvolvimento de determinada localidade, sendo que cada qual possui papel específico. Por isso, a inovação enquanto um dos fatores que indica o desenvolvimento de uma nação deve se inserir na realidade empreendedora a partir de uma agenda política que relacione os agentes para o desenvolvimento (MOURO, 2013, p. 28).

Por isso, Heidemann (2009) assevera a respeito das políticas públicas enquanto atos e fatos que devam atender os anseios da sociedade a partir de decisões e ações de governo em consonância com a participação de atores sociais nesse processo, seja de identificação das demandas sociais, seja de avaliação de políticas já consagradas. Significa que o papel do governo para direcionar ações de desenvolvimento local, por meio de políticas públicas, é importante para estabelecer os nortes para a cooperação, competição, produção, renda e desenvolvimento.

O Ministério de Ciência e Tecnologia e Inovação (MCTI) enfatiza a importância da relação entre universidades e os setores produtivos, tendo em vista a indissociável relação entre a pesquisa científica e tecnológica com o desenvolvimento econômico. Assim, além da importância fundamental das instituições de ensino e pesquisa, vários outros agentes são promotores do empreendedorismo e inovação na sociedade, tais como: a FINEP (Agência Brasileira de Inovação); o SEBRAE (Serviço Brasileiro de Apoio às Micro e Pequenas Empresas); a ANPEI (Associação Nacional 
de Pesquisa e Desenvolvimento de Empresas Inovadoras); a ANPROTEC (Associação Nacional de Entidades Promotoras de Empreendimentos Inovadores); dentre tantas outras que se unem para o aprimoramento da inovação tecnológica (MOURO, 2013, p. 28).

Contudo, ainda que existam diversos estudos estratégicos sobre empreendedorismo e inovação, inclusive conferências, congressos e seminários a respeito do tema, acredita-se que a efetividade das ações ainda merecem investimentos e ações mais consistentes. De qualquer sorte, o papel do governo em mediar e orientar o direcionamento de ações para o desenvolvimento inovativo e tecnológico é fundamental para o processo (OBAPL, 2014).

Os estudos sobre desenvolvimento local podem estar constantemente fundamentados em alicerces ortodoxos e inconsistentes, tais como políticas de infraestrutura, migrações como mecanismos de ajustes, e estratégias centrais de crescimento. Contudo, faz-se importante o papel do Estado para estimular as iniciativas locais, especialmente por meio de apoios financeiros, acesso à informação, transparência, e participação social (COFFEY; POLĖSE, 1985).

Portanto, o MCTI, juntamente com órgãos e agentes da sociedade civil organizada, tem elaborado ações para alimentar o sistema de inovação, ciência e tecnologia para o desenvolvimento econômico: eventos Pró-Inova; capacitações a empresas; cooperação entre empresa e universidade; financiamentos e fontes de fomento; incubadoras de empresas e parques tecnológicos; incentivos fiscais e subvenções econômicas (incentivos financeiros); entre outras ações (MCTI, 2013).

Não se pode, ainda, deixar de mencionar os ambientes e dinâmicas de cooperação para inovação, tendo em vista a rede que se cria a partir da união de esforços. Portanto, a cooperação e alianças estratégicas, numa relação de confiança e satisfação de interesses, estão presentes na formação de redes. Por conseguinte, a partir dos interesses firmados, faz-se importante as discussões acerca da territorialidade e das dimensões de influência dos atores do desenvolvimento (NASCIMENTO; LABIAK JUNIOR, 2011).

Os ambientes de inovação e empreendedorismo podem ser caracterizados como suportes para o desenvolvimento, a partir de ações e projetos a serem trabalhados em habitats denominados como pré-incubadoras, incubadoras de empresas e parques tecnológicos (NASCIMENTO; LABIAK JUNIOR, 2011).

Diante das discussões e estudos existentes acerca da inovação e empreendedorismo no desenvolvimento econômico, faz-se mister delimitar as potencialidades regionais para a organização e entrelaçamento de características que possam fortalecer e induzir o desenvolvimento local. Diante disso, as políticas devem atender a critérios e características regionais que reforcem e valorizem tais especificidades territoriais (GALVÃO, 2004).

\section{Resultados e discussões: os APL no Estado do Paraná}

Como forma de ilustrar o estudo acerca da formação de arranjos e sistemas produtivos locais, faz-se a demonstração de alguns dados para a identificação e estudo de potenciais forças empreendedoras para o desenvolvimento local, aproveitando-se das demandas e necessidades de uma delimitação espacial. Para tanto, buscou-se informações do Estado do Paraná, como objeto exemplificativo de estudo. 
O Paraná firmou Termo de Cooperação Geral, em 31 de janeiro de 2005, implantando a Rede de Apoio aos Arranjos Produtivos Locais do Estado do Paraná (Rede APL), cujos signatários foram o Estado do Paraná, a Agência de Fomento do Estado do Paraná (AFPR), Banco Regional de Desenvolvimento do Extremo Sul (BRDE), Federação das Indústrias do Estado do Paraná (FIEP), Serviço Social da Indústria (SESI/PR), Instituto Euvaldo Lodi (IEL/PR), Serviço Nacional de Aprendizagem Industrial (SENAI/PR), e o Serviço de Apoio às Micro e Pequenas Empresas do Paraná (SEBRAE/PR) (MDIC, 2013).

O órgão oficial do Governo Federal instituído para centralizar informações acerca dos Arranjos Produtivos Locais é o Observatório Brasileiro de Arranjos Produtivos Locais (OBAPL), apoiado por 27 Núcleos Estaduais de Apoio aos APL. Por meio do OBAPL, é possível conhecer a rede de APL em todo território nacional, sendo disponibilizados documentos e dados, além de contatos diretos com os Núcleos Estaduais de Apoio aos APL (OBAPL, 2014).

Trata-se de se conhecer ambientes negociais de coopetição, cujas relações internas e externas estão imbuídas de atividades cooperativas ou competitivas, dependendo do grau de interesses e da formatação estrutural das organizações. Significa que a complexidade e heterogeneidade das organizações, bem como de suas estruturas sociais para se relacionarem externamente são pontos relevantes para a compreensão do estudo (TSAI, 2002, p. 179).

O mapeamento e acompanhamento dos APL do Estado do Paraná por meio do Instituto Paranaense de Desenvolvimento Econômico e Social (IPARDES) e da Secretaria de Estado do Planejamento e Coordenação Geral (SEPL) do Paraná foram realizados em 2006 de acordo com fatores relevantes de APL validados, demonstrados no Quadro 03.

Quadro 03 - Relação dos APL validados pela SEPL e Ipardes

\begin{tabular}{|c|c|c|c|}
\hline $\mathrm{N}$. & APL & Local & Fatores relevantes \\
\hline 1. & $\begin{array}{l}\text { Aparelhos, } \\
\text { instrumentos e } \\
\text { equipamentos } \\
\text { médicos, } \\
\text { odontológicos e } \\
\text { hospitalares. }\end{array}$ & $\begin{array}{l}\text { Região } \\
\text { Metropolitana } \\
\text { de Curitiba } \\
\text { (RMC) }\end{array}$ & $\begin{array}{l}\text { Potencial inovativo e exportador; ineditismo } \\
\text { de produtos; e integração horizontal e } \\
\text { aglomeração de MPMEs. }\end{array}$ \\
\hline 2. & Cal e calcário & $\begin{array}{l}\text { Região } \\
\text { Metropolitana } \\
\text { de Curitiba } \\
\text { Norte }\end{array}$ & $\begin{array}{l}\text { Organização institucional local; inserção no } \\
\text { CT mineral; relevância na produção nacional. }\end{array}$ \\
\hline 3. & Confecções - bonés & Apucarana & $\begin{array}{l}\text { Governança local; especialização de produto } \\
\text { (bonés); importância das MPME. }\end{array}$ \\
\hline 4 . & $\begin{array}{l}\text { Confecções - Moda } \\
\text { bebê }\end{array}$ & Terra Roxa & $\begin{array}{l}\text { Governança local; especialização de produto } \\
\text { (moda bebê); importância das MPME e nível } \\
\text { tecnológico relativamente homogêneo. }\end{array}$ \\
\hline 5 . & Confecções & Cianorte & $\begin{array}{l}\text { Governança local; especialização de produto } \\
\text { (jeans e modinha); modelo de } \\
\text { comercialização inovador (ASAMODA). }\end{array}$ \\
\hline 6. & Confecções & Maringá & $\begin{array}{l}\text { Organização institucional regional e estadual } \\
\text { (Sindivest e Vestpar); várias classes } \\
\text { industriais relacionadas; importância de } \\
\text { MPME. }\end{array}$ \\
\hline 7. & Confecções & Sudoeste do & Organização institucional regional; ambiente \\
\hline
\end{tabular}


Quadro 03 - Relação dos APL validados pela SEPL e Ipardes

\begin{tabular}{|c|c|c|c|}
\hline & & Paraná & propício à cooperação; protagonismo local. \\
\hline 8. & $\begin{array}{l}\text { Equipamentos e } \\
\text { implementos } \\
\text { agrícolas. }\end{array}$ & $\begin{array}{l}\text { Cascavel e } \\
\text { Toledo }\end{array}$ & $\begin{array}{l}\text { Especialização regional no segmento de } \\
\text { equipamentos e implementos agrícolas; } \\
\text { segmento com potencial inovador; inter- } \\
\text { relações produtivas entre as empresas } \\
\text { (embora não percebidas pelos atores). }\end{array}$ \\
\hline 9. & Louças e porcelanas & Campo Largo & $\begin{array}{l}\text { Especialização de produto (louça e } \\
\text { porcelana); inserção no Exporta Cidade; } \\
\text { principal produtor nacional. }\end{array}$ \\
\hline 10. & Madeiras e esquadrias & $\begin{array}{l}\text { União da } \\
\text { Vitória }\end{array}$ & $\begin{array}{l}\text { Maior produtor nacional de esquadrias de } \\
\text { madeira; produtos em potencial exportador; } \\
\text { ações em desenvolvimento. }\end{array}$ \\
\hline 11. & Malhas & Imbituva & $\begin{array}{l}\text { Especialização e produto (malhas); } \\
\text { organização institucional local } \\
\text { (Imbitumalhas); aglomeração de MPME e } \\
\text { nível tecnológico relativamente homogêneo. }\end{array}$ \\
\hline 12. & Mandioca e Fécula & Paranavaí & $\begin{array}{l}\text { Especialização de produto (fécula } \\
\text { modificada); organização institucional local; } \\
\text { forte relação com setor agrícola. }\end{array}$ \\
\hline 13 . & Metais sanitários & Loanda & $\begin{array}{l}\text { Especialização de produto (torneiras de } \\
\text { metal); inter-relações produtivas entre as } \\
\text { empresas; liderança e maior produtor do } \\
\text { Estado. }\end{array}$ \\
\hline 14. & Móveis & Arapongas & $\begin{array}{l}\text { Maior polo moveleiro do Estado e de forte } \\
\text { expressão nacional; importância de MPME; } \\
\text { potencial exportador. }\end{array}$ \\
\hline 15 . & Móveis & Sudoeste & $\begin{array}{l}\text { Organização institucional; ambiente propício } \\
\text { à cooperação; potencial inovativo e } \\
\text { exportador. }\end{array}$ \\
\hline 16. & Móveis e madeira & Rio Negro & $\begin{array}{l}\text { Móveis de alto padrão, exportados para } \\
\text { mercados dinâmicos; cadeira local, matéria- } \\
\text { prima de alto rendimento; protagonismo } \\
\text { local espontâneo, sem apoio institucional. }\end{array}$ \\
\hline 17. & $\begin{array}{l}\text { Móveis de metal e } \\
\text { sistemas de } \\
\text { armazenagem e } \\
\text { logística }\end{array}$ & Ponta Grossa & $\begin{array}{l}\text { Potencial inovativo; especialização local, } \\
\text { conhecimento tácito; produçãa diferenciada. }\end{array}$ \\
\hline 18. & Software & $\begin{array}{l}\text { Curitiba, } \\
\text { Londrina, } \\
\text { Maringá, Pato } \\
\text { Branco e Dois } \\
\text { Vizinhos } \\
\end{array}$ & $\begin{array}{l}\text { Atividade inovadora e prioritária na PITCE; } \\
\text { transversalidade; importância da produção } \\
\text { estadual no país. }\end{array}$ \\
\hline
\end{tabular}

Fonte: SEPL, IPARDES (IPARDES; SEPL, 2006, p. 57).

De forma a ilustrar a distribuição espacial dos APL no Estado do Paraná, de acordo com o Quadro 03, demonstra-se o mapeamento realizado pela SEPL conforme Figura 03. 


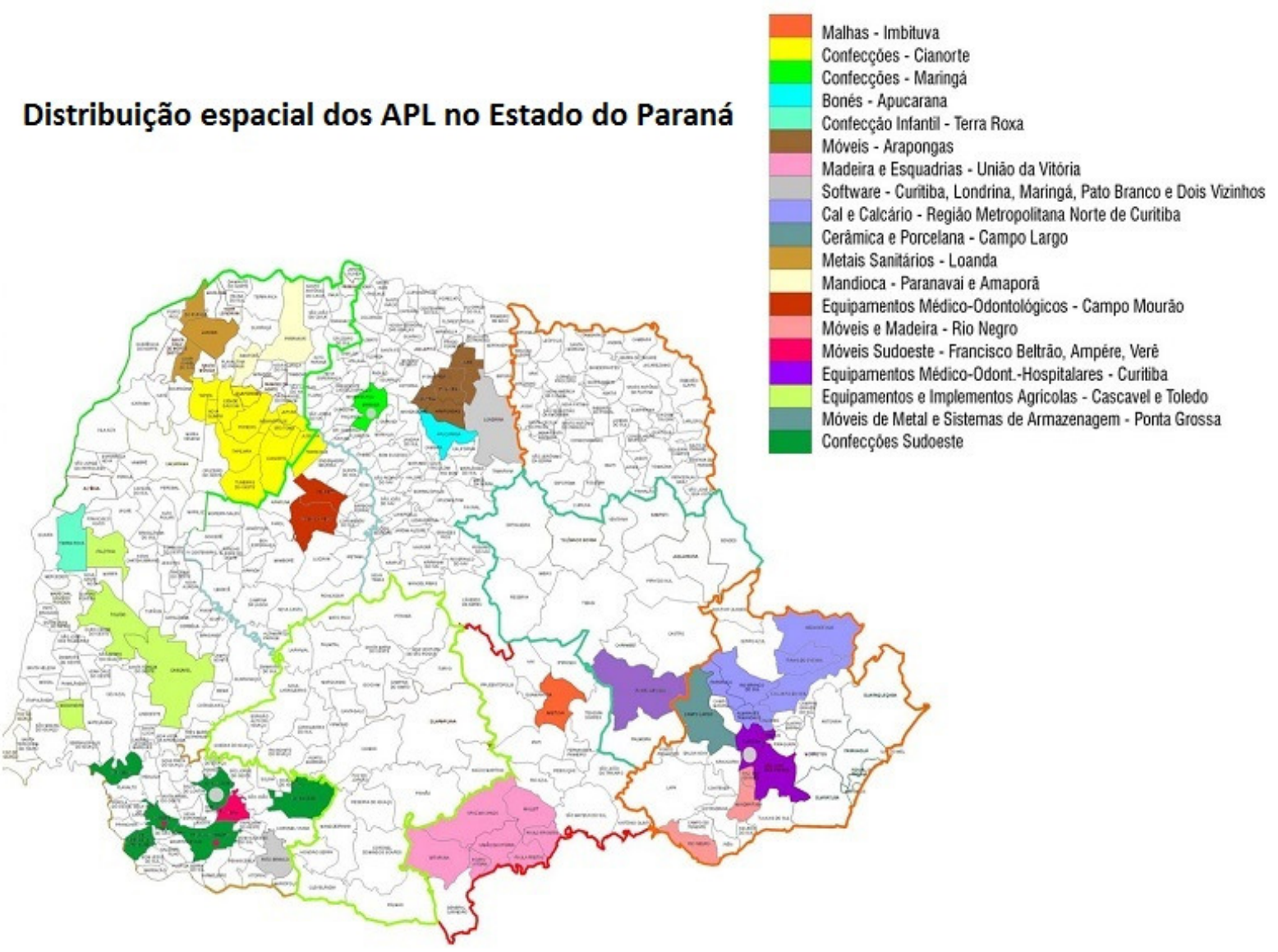

Figura 03 - Distribuição espacial dos APL no Estado do Paraná Fonte: SEPL apud BRASIL (2014).

Em 2009 o Ipardes realizou novo estudo de identificação de APL, atualizando os dados da pesquisa de 2006, demonstrando uma relação de 126 aglomerações produtivas no Paraná e seus indicadores como potenciais forças para a constituição de um APL (IPARDES, 2009). Constata-se, então, a caracterização de APL a partir de critérios pertinentes, observando-se a espacialidade entre os APL distribuídos no território do Estado do Paraná (Figura 03), configurando eventuais bolsões inexplorados no centro e nordeste do Estado. Trata-se em induzir, acompanhar, avaliar e fortalecer a coopetição entre as potencialidades ou aglomerações produtivas nos territórios a partir da observação dos elementos naturais, humanos, empresariais e de $\mathrm{P} \& \mathrm{D}$ nas regiões.

Nesse sentido, e em que pese às instituições promotoras dos APL terem destacado a ausência de ações da Rede APL do Paraná desde 2009, foi em 2012 que ocorreu um Workshop de Planejamento Estratégico para estabelecer novos rumos para o desenvolvimento dos APL. No evento foram mapeados os pontos positivos, negativos e as expectativas em relação à Rede. Já em dezembro de 2013, ocorreu em Brasília a $6^{\mathrm{a}}$ Conferência Brasileira de Arranjos Produtivos Locais, como sinal de fortalecimento e crescimento das discussões acerca das aglomerações produtivas (MDIC, 2013; OBAPL, 2014).

Entende-se que eventos, congressos, conferências, seminários e palestras são mecanismos importantes para reunir os agentes e instituições inter-relacionados, bem como para aproximar, discutir e aprimorar as ações e estratégicas para o desenvolvimento do empreendedorismo no país (FILION; LAFERTÉ, 2003). 
Pelos dados do IBGE, a capital paranaense possuía em 2010 a quantia de 1.751.907 habitantes, sendo 995.543 a população economicamente ativa, e 947.196 a população ocupada; já a região metropolitana de Curitiba possuía 3.223.836 habitantes em 2010, sendo 1.768 .624 a população economicamente ativa da região, e 1.681.455 a população ocupada. Em Curitiba, das 947.196 pessoas ocupadas, $18,7 \%$ estão lotadas no "comércio, reparação de veículos automotores e motocicletas"; 12,9\% na "indústria de transformação"; 6,6\% na "educação"; 5,8\% na "construção"; 5,8\% em "atividades profissionais, científicas e técnicas". Apenas essas cinco atividades econômicas representam 49,8\% das atividades exercidas pela população ocupada de Curitiba (IPARDES, 2013).

Já em relação ao número de estabelecimentos e de empregos existentes no município de Curitiba, de acordo com dados do MTE/RAIS 2012, verifica-se que a indústria (em seus diversos segmentos) representa $8 \%$ de todos os estabelecimentos segundo as atividades econômicas de Curitiba, o que importa em 11,1\% dos empregos disponíveis no município. Os setores da indústria que mais se destacam em números de estabelecimentos são: metalúrgica (17,2\% dos estabelecimentos industriais); indústria de produtos alimentícios, de bebida e álcool etílico (13,7\%); indústria do papel, papelão, editorial e gráfica (13,7\%); indústria têxtil, do vestuário e artefatos de tecidos $(10,6 \%)$; indústria mecânica $(10,2 \%)$. Já os setores da indústria com maior número de oferta de empregos são: indústria mecânica $(18,5 \%$ dos empregos da indústria); indústria de materiais de transporte (12,8\%); indústria do papel, papelão, editorial e gráfica (10,6\%); indústria metalúrgica $(9,4 \%)$; e indústria de materiais elétricos e de comunicação (9,5\%) (IPARDES, 2013).

Desses dados quantitativos, uma pesquisa acadêmica levantou os benefícios dos APL no desenvolvimento local do Estado do Paraná em relação à atividade econômica de softwares. O estudo avaliou os impactos da descentralização de políticas públicas para o desenvolvimento local no Estado do Paraná no período 2003 a 2009. Concluiu-se, então, que a relação dos APL com o número de emprego na atividade econômica de softwares é significativa: O APL de Curitiba, em 2009, apresentou 64\% dos empregos desta atividade econômica; sendo, ainda, a soma dos APL de Curitiba, Londrina, Maringá e Sudoeste equivale a $81 \%$ das atividades nessa área no Estado (MARINI; SILVA, 2012).

A presente pesquisa também se atentou em entrevistar a "Assessora técnica de planejamento", da Coordenação de Desenvolvimento Governamental, da Secretaria do Planejamento e Coordenação Geral do Estado do Paraná (SEPL) para discutir a respeito dos APL. A metodologia de pesquisa deveu-se por meio de agendamento prévio para entrevista oral, gravada, na data de 17 de janeiro de 2014, nos aposentos da SEPL, sito à Rua Jacy Loureiro de Campos, s/n - $4^{\circ}$ and - Centro Cívico, Curitiba, Paraná, por meio de questionamentos e discussões acerca do tema.

Dos assuntos tratados, consideram-se os mais relevantes para o entendimento dos APL no Estado do Paraná os seguintes: a) a profundidade do envolvimento de prefeituras municipais, bem como de instituições públicas ou privadas nos APL tem direta relação à maturidade desses agentes e das empresas, os quais devem saber lidar com a cooperação e competitividade natural das mesmas; b) as aglomerações produtivas (enquanto um momento anterior à formação de um APL) podem surgir de forma espontânea ou induzida; c) há em outros Estados casos de APL serem constituídos por associações ou cooperativas, formando-se, então, pessoas jurídicas capazes de gerar recursos próprios; d) não há obrigatoriedade de assinatura de um termo para formação de um APL, mas tal instituto deve cumprir alguns requisitos de governança, de cooperação, de indicadores e de outras características recomendadas 
por órgãos envolvidos (SEPL, Rede APL, IPARDES, SEBRAE, MDIC, etc.); e) há necessidade de definição das potencialidades das aglomerações produtivas nos níveis federal, estadual e municipal de forma que se estabeleça o que é interessante e factível para o desenvolvimento local; f) faz-se importante entender as ações e entendimentos de outros órgãos que lidam com outras searas do conhecimento (SEBRAE, Secretaria de Ciência e Tecnologia do Estado do Paraná - SETI, IPARDES, BNDES, Ministérios, etc.).

Portanto, a ilustração acerca dos APL é ferramenta importante para se compreender a importância desses arranjos no desenvolvimento local, bem como conhecer a interação, maturidade, potencialidades, organização, funcionamento e contribuições que esses complexos cometem à sociedade. Trata-se em relatar as cooperações necessárias para o progresso e sucesso do empreendedorismo em determinada delimitação territorial, cujos reflexos são variáveis em sentido econômico, social e ambiental.

\section{Considerações Finais}

A pesquisa científica é forte aliada do desenvolvimento econômico e social de uma sociedade, muito embora tenha ainda mais espaço para presentes e futuras contribuições no Brasil. A relação Universidade, indústria e governo já destacado por Etzkowitz e Leydesdorff (1995) sempre foi uma realidade dos países desenvolvidos, já que tinham a noção dos papéis das instituições de ensino e pesquisa, juntamente com o governo, como indutores e promotores do desenvolvimento.

Ao empresariado e à indústria falta espaço para administrar questões macroeconômicas, diferentemente de outras entidades que podem direcionar esforços para uma visão holística da situação econômica, criando-se novos rumos e novas estratégias. Por isso, as instituições de ensino e pesquisa possuem papel apropriado para a discussão e experimentação de novos horizontes do desenvolvimento, devendo-se propor projetos que sejam diretamente direcionados ao fortalecimento da indústria, do empreendedorismo e da inovação. Culturalmente, todavia, ainda há barreiras quanto à relação Universidade-empresa, em especial as instituições públicas, mas que devem ser desvencilhadas para contribuírem cada vez mais para ganhos econômicos, sociais e ambientais.

Desta feita, a partir de uma lógica capitalista de desenvolvimento, respeitando também os ganhos sociais e humanitários enquanto garantias do Estado, há que se estabelecerem as metas de desenvolvimento dentro da complexidade e das variáveis existentes para tanto. Por isso, entende-se que a lógica dos arranjos produtivos locais, bem como as relações e compreensões acerca da coopetição entre agentes de desenvolvimento, podem induzir o progresso de uma delimitação espacial de forma mais eficaz, sem elidir a presença de influências da globalização do comércio e da produção.

Os APL possuem o apelo de manter o emprego, utilizar a matéria-prima, e gerar o capital dentro de uma localidade, o que acarreta em ganhos econômicos. Contudo, a indução para a criação da rede, parques tecnológicos ou de um sistema de aglomeração produtiva deve ser incentivada pelo governo por meio de políticas públicas concretas e planejadas, em que estejam presentes as linhas de cooperação e competição entre os agentes. Tais são os papéis, também, das organizações não governamentais e da sociedade civil organizada que visam estabelecer os elos entre os agentes promotores dos APL. Acredita-se que é incipiente a indução de aglomerações

Informe Gepec, Toledo, v. 18, n. 2, p. 66-85, jul./dez. 2014 
produtivas de forma organizada e planejada, tendo em vista que, geralmente, a formação dessas aglomerações ocorre de maneira espontânea e desorientada.

Diante de tal prisma, verifica-se que a realidade brasileira tem caminhado para instituir políticas que fortaleçam os APL, o que pode ser observado nas próprias ações dos Ministérios do Desenvolvimento, Indústria e Comércio Exterior (MDIC), bem como do Ministério da Ciência, Tecnologia e Inovação (MCTI).

No entanto, o presente estudo pretendeu demonstrar uma das possibilidades de desenvolvimento econômico por meio da valorização das potencialidades locais, o que pode gerar um crescimento em escala. As discussões acerca dos APL são multifacetadas, dada à complexidade das variáveis existentes. Por isso, ainda que não seja possível reunir todos os estudos acerca de arranjos produtivos locais e empreendedorismo em um único, ficam as reflexões a fim de agregar novas propostas, tais como o avanço tecnológico globalizado para a produção industrial, construção civil, bem como para a inovação e eficiência de novos processos e produtos.

Por fim, embora seja possível identificar as aglomerações produtivas nos territórios, inclusive por meio de órgãos oficiais de governo, faz-se importante a discussão entre os agentes promotores dos APL para averiguar os interesses econômicos e sociais envolvidos, assim como as vantagens e reais potencialidades para o desenvolvimento de determinados produtos ou serviços.

\section{Referências}

BENGTSSON, Maria; KOCK, Sören. "Coopetition" in business Networks - to cooperate and compete simultaneously. Industrial marketing management, v. 29, n. 5, p. 411-426, 2000.

BENKO, Georges; PECQUEUR, Bernard. Os Recursos de Territórios e os Territórios de Recursos. Geosul, v. 16, n. 32, p. 32-50, 2009.

BRANDENBURGER, Adam M.; NALEBUFF, Barry J. Co-opetition. Random House Digital, Inc., 2011.

BRASIL. Ministério do Desenvolvimento, Indústria e Comércio Exterior. <http://www.mdic.gov.br/sitio/interna/interna.php?area=2\&menu=300 > Acesso em 10 dez 2013.

BRASIL. Ministério do Desenvolvimento, Indústria e Comércio Exterior. Rede de Apoio aos Arranjos Produtivos Locais do Estado do Paraná. $<$ http://www.mdic.gov.br/sitio/interna/interna.php?area $=2 \& m e n u=300>\quad$ Acesso em 10 dez 2013.

BRASIL. Ministério do Desenvolvimento, Indústria e Comércio Exterior. Rede de Apoio aos Arranjos Produtivos Locais do Estado do Paraná. $<$ http://www.mdic.gov.br/sitio/interna/interna.php?area=2\&menu=300 $>$ Acesso em 10 dez 2013.

BRASIL. Ministério do Desenvolvimento, Indústria e Comércio Exterior. Rede de Apoio aos Arranjos Produtivos Locais do Estado do Paraná. <http://www.mdic.gov.br/arquivos/dwnl_1198692481.pdf> Acesso em o9 ago 2014. 
BRASIL. Ministério da Ciência, Tecnologia e Inovação. <http://www.mct.gov.br/index.php/content/view/73411/II_Promocao_da_Inovaca o_Tecnologica_nas_Empresas.html > Acesso em $10 \mathrm{dez} 2013$.

BRASIL. Observatório Brasileiro de Arranjos Produtivos Locais (OBAPL). $<$ http://portalapl.ibict.br/index.html >. Acesso em 04 jan 2014.

CÂNDIDO, Gesinaldo Ataíde. Fatores críticos de sucesso no processo de formação, desenvolvimento e manutenção de redes interempresariais do tipo agrupamento industrial entre pequenas e médias empresas: um estudo comparativo de experiências brasileiras. 2001. Tese de Doutorado. Universidade Federal de Santa Catarina, Centro Tecnológico, Programa de Pósgraduação em Engenharia de Produção, Florianópolis, 2001.

CASSIOLATO, José Eduardo; LASTRES, Helena M. M. Glossário de arranjos e sistemas produtivos locais. Sebrae. Rio de Janeiro: UFRJ, 2003.

CASSIOLATO, José Eduardo; LASTRES, Helena M. M. O foco em arranjos produtivos e inovativos locais de micro e pequenas empresas. Pequena empresa: cooperação e desenvolvimento local. Rio de Janeiro: Relume Dumará, p. 21-34, 2003.

COFFEY, William J.; POLÈSE, Mario. Local development: Conceptual bases and policy implications. Regional studies, v. 19, n. 2, p. 85-93, 1985.

COSTA, Eduardo José Monteiro da. Arranjos Produtivos Locais, Políticas Públicas e Desenvolvimento Regional. Brasília: Mais Gráfica Editora, 2010.

CROCCO, Marco et al. Metodologia de identificação de arranjos produtivos locais potenciais: uma nota técnica. Cedeplar, Universidade Federal de Minas Gerais, 2003.

ETZKOWITZ, Henry; LEYDESDORFF, Loet. The triple helix-university-industrygovernment relations: a laboratory for knowledge-based economic development. EASST Review. 14 Ž . 1, 14-19, 1995.

ETZKOWITZ, Henry; LEYDESDORFF, Loet. The dynamics of innovation: from National Systems and "Mode 2" to a Triple Helix of university-industry-government relations. Research policy, v. 29, n. 2, p. 109-123, 2000.

ETZKOWITZ, Henry. Hélice Tríplice: universidade-indústriagoverno:inovação em movimento. Porto Alegre: Edipucrs, 2013.

FILION, Louis Jacques.; LAFERTÉ, Sylvie. Um roteiro para desenvolver o empreendedorismo. Tradução de: Fillion, L.J.; Lafetté, S. Carte routière pour un Québec entrepreneurial. Chaire d' entrepreneuriat Rogers - J.A.Bombardier. Raport remis au Gouvermement du Québec. HEC Montréal: Décember, 2003.

GALVÃO, Antonio Carlos Filgueira. Política de desenvolvimento regional e inovação: a experiência da União Europeia. Rio de Janeiro: Garamond, 2004.

HEIDEMANN, Francisco G. Do sonho do progresso às políticas de desenvolvimento. In: Heidemann, F. G. e SALM, J. F. (Orgs). Políticas públicas e 
desenvolvimento: bases epistemológicas e modelos de análise. Brasília: Editora UNB, 2009.

IPARDES. Identificação e mapeamento das aglomerações produtivas do Paraná. Curitiba: Ipardes, 2009.

IPARDES. Caderno estatístico Município de Curitiba. $<$ http://www.ipardes.gov.br/cadernos/Montapdf.php?Municipio=800oo\&btOk=ok $>$ Acesso em 10 dez. 2013.

IPARDES. SEPL. Arranjos Produtivos Locais do Estado do Paraná: identificação, caracterização e construção de tipologia. Instituto Paranaense de Desenvolvimento Econômico e Social. Secretaria de Estado do Planejamento e Coordenação Geral. Curitiba: Ipardes, 2006.

LAWTON SMITH, Helen; LEYDESDORFF, Loet. The Triple Helix in the context of global change: dynamics and challenges. Available at SSRN 2177331, 2012.

LEMOS, Cristina. Inovação em Arranjos e Sistemas de MPME. Rio de Janeiro, Universidade Federal do Rio de Janeiro, 2001.

MARINI, Marcos Junior; SILVA, Christian Luiz da. Desenvolvimento Regional e Arranjos Produtivos Locais: uma abordagem sob a ótica interdisciplinar. Revista Brasileira de Gestão e Desenvolvimento Regional, v. 8, p. 107-129, 2012.

MARINI, Marcos Junior; SILVA, Christian Luiz da. Políticas de descentralização no Estado do Paraná: Um estudo sobre o APL de software do sudoeste do Paraná EL CLUSTER DE SOFTWARE EN SUROESTE DE PARANA. Espacios (Caracas), v. 33, p. 1-22, 2012.

MOURO, Rosi. Um breve panorama das iniciativas de apoio à inovação no Paraná. Caderno INTEC 3 - Desenvolvimento empresarial, inovação e tecnologia. Curitiba: Tecpar Intec, 2013.

NASCIMENTO, Décio Estevão do; LABIAK JUNIOR, Silvestre. Ambientes e dinâmicas de cooperação para inovação. Série UTFinova. Curitiba: Aymará, 2011.

PERROUX, François. Economic space: theory and applications. The Quarterly Journal of Economics, v. 64, n. 1, p. 89-104, 1950.

PLONSKI, Guilherme Ary. Bases para um movimento pela inovação tecnológica no Brasil. São Paulo Perspec. [online]. 2005, vol.19, n.1, pp. 25-33. ISSN 0102-8839.

PORTER, Michael. Clusters and the new economics of competition. Watertown: Harvard Business Review, 1998.

PORTER, Michael. Estratégia competitiva. 2. ed. Rio de Janeiro: Elsevier, 2004.

SEBRAE. Termo de referência para atuação do sistema SEBRAE em arranjos produtivos locais. Brasília: Sebrae, 2003.

THEIS, Ivo Marcos; GALVÃO, Antônio Carlos Filgueira. A formulação de políticas públicas e as concepções de espaço, território e região. Revista Brasileira de Estudos Urbanos e Regionais. V. 14, n. 2, nov. 2012, p. 55-69 
TSAI, Wenpin. Social structure of "coopetition" within a multiunit organization: Coordination, competition, and intraorganizational knowledge sharing. Organization science, v. 13, n. 2, p. 179-190, 2002.

Submetido em 29/o7/2014.

Sobre os autores

Aprovado em 25/o9/2014.

\section{Tiago Hideki Niwa}

Mestrando em Planejamento e Governança Pública - PPGPGP; Pós-graduação Lato sensu em Direito Aplicado pela Escola da Magistratura do Paraná; Graduação em Direito pela Universidade Estadual de Londrina. Servidor público federal, exerce o cargo de Auditor na Universidade Tecnológica Federal do Paraná - UTFPR.

Email: tiago.niwa@gmail.com

\section{Isaura Alberton de Lima}

Graduação em Administração pela Universidade Estadual do Oeste do Paraná (1987). Mestre em Tecnologia pela UTFPR (1999). Doutora em Engenharia de Produção pela Universidade Federal de Santa Catarina (2004). Atualmente é professora da UTFPR.

Email: alberton@utfpr.edu.br

\section{Christian Luiz da Silva}

Professor do mestrado em planejamento e governança pública e do programa de mestrado e doutorado em Tecnologia da UTFPR. Economista, mestre e doutor em engenharia de produção pela UFSC e pósdoutor em administração pela Universidade de São Paulo (USP).

Email: christianlsilva76@gmail.com 